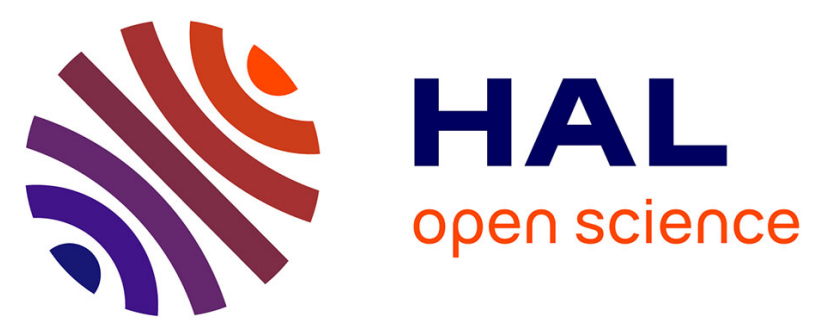

\title{
A Mathematical model for treatment of papillary thyroid cancer using the allee effect
}

Jairo Gomes da Silva, Rafael Martins de Morais, Izabel Cristina Rodrigues da Silva, Mostafa Adimy, Paulo Fernando de Arruda Mancera

\section{- To cite this version:}

Jairo Gomes da Silva, Rafael Martins de Morais, Izabel Cristina Rodrigues da Silva, Mostafa Adimy, Paulo Fernando de Arruda Mancera. A Mathematical model for treatment of papillary thyroid cancer using the allee effect. Journal of Biological Systems, 2020, 28 (03), pp.701-718. 10.1142/S0218339020500138 . hal-03167508

\section{HAL Id: hal-03167508 \\ https://hal.science/hal-03167508}

Submitted on 12 Mar 2021

HAL is a multi-disciplinary open access archive for the deposit and dissemination of scientific research documents, whether they are published or not. The documents may come from teaching and research institutions in France or abroad, or from public or private research centers.
L'archive ouverte pluridisciplinaire HAL, est destinée au dépôt et à la diffusion de documents scientifiques de niveau recherche, publiés ou non, émanant des établissements d'enseignement et de recherche français ou étrangers, des laboratoires publics ou privés. 


\title{
A MATHEMATICAL MODEL FOR TREATMENT OF PAPILLARY THYROID CANCER USING THE ALLEE EFFECT
}

\author{
JAIRO GOMES DA SILVA* \\ Programa de Pós-Graduação em Biometria, Universidade Estadual Paulista (UNESP) \\ Instituto de Biociências, Botucatu, SP, 18618-689, Brazil \\ jairo.gomes@unesp.br \\ RAFAEL MARTINS DE MORAIS \\ Imagens Médicas de Brasília (IMEB), Taguatinga, DF, 72115-700, Brazil \\ rafaelmartins.unb@gmail.com \\ IZABEL CRISTINA RODRIGUES DA SILVA \\ Universidade de Brasília (UnB), Faculdade de Ceilândia \\ Ceilândia Sul, DF, 72220-275, Brazil \\ belbiomedica@gmail.com \\ MOSTAFA ADIMY \\ Inria, Univ Lyon, Université de Lyon 1, Institute Camille Jordan \\ 43 Bd. du 11 novembre 1918, F-69200 Villeurbanne Cedex, France \\ mostafa.adimy@inria.fr \\ PAULO FERNANDO DE ARRUDA MANCERA \\ Universidade Estadual Paulista (UNESP), Instituto de Biociências \\ Botucatu, SP, 18618-689, Brazil \\ paulo.mancera@unesp.br
}

The incidence of thyroid cancer is rising all over the world, and the papillary subtype (PTC) is the primary factor for this increase. The presence of thyroid tumors is commonly associated with increased levels of cytokines, such as interleukin 6 (IL-6). Considering PTC patients treated with thyroidectomy and radioactive iodine ${ }^{131} \mathrm{I}$ (RAI), we propose an ordinary differential system using four variables: the RAI activity, the number of cancer cells and the serum concentrations of IL-6 and thyroglobulin (Tg). Our objective is to study the efficacy of different therapeutic doses of RAI in the treatment of thyroid cancer. The Allee effect is taken into account when modeling cancer cells growth under the influence of IL-6. From the results obtained, the main factors and conditions correlated with successful treatment, such as the RAI activity used and the tumor response are addressed. The detection of minimal doses of RAI that can cause tumor extinction is performed, though this has also meant longer periods for tumor cell elimination. The critical number of tumor cells due to the Allee effect is analyzed and linked to the immune system or biological factors that can slow the progression of the tumor but are

\footnotetext{
${ }^{*}$ Corresponding author.
} 
2 da Silva, Morais, Silva, Adimy \& Mancera

insufficient after thyroid resection surgery.

Keywords: Thyroid tumor; Interleukin 6; Radioiodine; Ordinary differential equations.

\section{Introduction}

The number of thyroid cancer diagnoses in the United States is predicted to exceed that of colorectal cancer by $2030,{ }^{1}$ making it the fourth most prevalent cancer. Despite this, a simultaneous increase in the number of thyroid cancer-related deaths is not predicted. ${ }^{2}$ When weighing the evidence of the higher number of small tumors diagnosed and the improved or unchanged survival rate, most studies attribute the increased incidence to an overdetection of papillary thyroid cancer (PTC), ${ }^{3}$ whereas some studies consider that it's more than a case of overdetection but an actual increase in the numbers of tumors. ${ }^{4,5}$ The PTC is by far the most common histological subtype, representing $90 \%$ of differentiated thyroid carcinomas (DTC) and $85-90 \%$ of all thyroid cancers. ${ }^{6,7}$

The American Thyroid Association (ATA) guidelines ${ }^{8}$ recommend thyroid lobectomy or thyroidectomy surgery, if the cytology results indicate a primary thyroid malignancy. Though, in some cases, only an active surveillance management approach may be endorsed. After surgery, the RAI remnant ablation depends on many factors, e.g., the presence of local or distant metastases, locoregional tumor invasion, aggressive histology, among others. However, this treatment is not routinely recommended after thyroidectomy for PTC patients classified with low risk of recurrence, as seen in Ref. 8. In PTC, this therapy is frequently used for the following purposes: residual thyroid tissue elimination; adjuvant therapy, due to its potential tumoricidal effect; resource for a post-treatment full-body scan to find unknown metastases; and therapy in the case of persistent disease.

RAI therapy has been used, since the 1940s, for both malignant and benign thyroid conditions, such as hyperthyroidism due to Graves' disease, toxic multinodular goiter, and hyperfunctioning thyroid nodules. ${ }^{9}$ According to Wishart et al. ${ }^{10}$ the iodine-131 causes mutation and death in cells due to its mode of beta decay, and its therapeutics effects are a result of the ionizing radiation absorbed by the thyroidal tissue. Although the thyroid gland naturally uptakes iodine from the body, the success of RAI treatment for PTCs depends on how much iodine is taken up by iodide transporter of the thyroid. I-131 uptake is almost entirely done by the thyroid gland, and so only an insignificant amount of radiation exposure occurs outside the gland. ${ }^{10}$ Among the ways to evaluate response to RAI therapy in PTC, analysis of thyroglobulin ( $\mathrm{Tg}$ ) levels are indicated. ${ }^{11,12}$ For instance, an excellent response to the treatment with total thyroidectomy and RAI ablation in PTC patients is if the thyrotropin-stimulated $\mathrm{Tg}$ is lower than $1 \mathrm{ng} / \mathrm{mL}$ in the absence of anti- $\mathrm{Tg}$ antibodies. $^{8}$

The immune system is a significant agent in cancer regulation, which can both prevent or facilitate tumor progression. According to Dunn et al. ${ }^{13}$ and Yu et al. ${ }^{14}$ the manner in which tumor cells escape immune system surveillance must be under- 
stood primarily from an immunosuppressive dysfunction perspective, for instance, a dysregulation of Tregs cells, immunomodulatory cytokines or both. Interleukin 6 (IL-6) is a cytokine that plays a central role in the regulation of inflammatory, immune and hematopoietic processes ${ }^{15}$ and has been the target of several studies regarding its influence on various types of tumor malignancy, including thyroid cancer. ${ }^{16-21}$ Provatopoulou et al. ${ }^{22}$ observed IL-6 levels significantly higher than baseline levels $(2.19 \pm 3.30$ vs $5.42 \pm 9.76, p=0.006)$ in thyroid cancer patients and proposed its use among other cytokines to understand the mechanisms underlying the disease. Working on the significance of IL-6 in papillary thyroid carcinomas, Kobawala et al. ${ }^{19}$ noted that, in addition to increased levels, this cytokine was generally associated with a lower survival rate of PTC patients, playing an essential role in disease progression.

To study tumor growth, in addition to the mathematical models employing exponential, logistic or Gompertz equations ${ }^{23}$ some studies adopted a law of population ecology known as the Allee effect. ${ }^{24-28}$ According to Stephens et al. ${ }^{29}$ this concept established by W. C. Allee in the 1930s, refers to a fact observed in some populations in which there is extinction below a certain threshold. In general, this phenomenon is marked by the existence of an unstable equilibrium, where below it the growth is negative. ${ }^{30}$ Among the recent studies using the Allee effect for cancer research, Korolev et al. ${ }^{24}$ considered tumor cells as an endangered species to find potential vulnerabilities related to extinction processes. In their paper, they used concepts from conservation biology, ecology, and evolution to identify mechanisms that can lead cancer to extinction or inhibit its adaptation. Moreover, the use of the Allee effect in processes such as cancer cell cooperative behavior until tumor recurrence in glioblastoma, ${ }^{28}$ population growth kinetics in small tumors ${ }^{25}$ tumor growth and necrotic core formation ${ }^{26}$ have been acknowledged.

Mathematical modeling has long been used in cancer biology research. ${ }^{31-34}$ Until 2018, most models of thyroid cancer used ordinary differential equations. ${ }^{35}$ They have been used to investigate thyroid cancer in terms of diagnosis, treatment or follow-up of patients with neoplasms (see also Refs. 36-40). In another study, ${ }^{41}$ a linear-quadratic model was employed to optimize the amount of RAI $\left({ }^{131} \mathrm{I}\right)$ to be applied in cases of remaining thyroid cells after surgery or in the presence of metastasis. The evaluation of the effective half-life of radioactive iodine in different compartments of the human body, and a criteria proposal to classify patients with thyroid cancer as responders or not to RAI treatment also used ordinary differential models. ${ }^{40,42}$ Considering RAI treatment after thyroidectomy in PTC patients and metastasis, Barbolosi et al. ${ }^{42}$ constructed a mathematical model to evaluate the effectiveness of RAI treatment. From the results obtained, a classification criterion was created based on the parameter associated with the tumor doubling-time under treatment to recognize patients as responders or non-responders to RAI in the early stages of therapy. The proposed model is a system composed of three ordinary differential equations using the variables: the RAI activity, the number of cancer cells and the thyroglobulin concentration. The serum $\mathrm{Tg}$ concentration at time in 
the blood was used as a means to assess treatment efficacy.

Taking into account the tumor cell proliferation driven by the Allee effect and IL-6 influence, we propose a mathematical model to evaluate the efficacy of RAI treatment in PTC. The amount of interleukin 6 considered excessive is produced by the tumor mass and also stimulated by the RAI administration. The success of the treatment is analyzed based on the number of cancer cells and serum $\mathrm{Tg}$ concentration over time. From linear stability analysis and numerical simulations, we discuss scenarios in which parameters representing the applied RAI dose, IL-6 levels, and critical tumor cell number are recognized as key factors for success or not of the treatment.

This paper is structured as follows: in Section 2, we present the proposed mathematical model and its parameters. In Section 3, we discuss the positivity and the existence of equilibrium points of the model and the influence of parameter $Q$ in the absence of RAI treatment. In Section 4, we consider the introduction of the RAI treatment in simulations. In Section 5, we present our results and discussions. Finally, Section 6 closes the article with the main conclusions to the area of study.

\section{Mathematical Model}

In this model, the study of RAI effectiveness in the PTC treatment is based on four variables depending on time $t$. Denoting by $A$ the RAI activity, by $N$ the number of the cancer cells, by $I$ the IL- 6 and by $T_{g}$ the thyroglobulin, both with serum concentrations over time, the model proposed is as follows:

$$
\left\{\begin{array}{l}
\frac{d A}{d t}=-a \log (2) A \\
\frac{d N}{d t}=\alpha(1-k \exp (-\beta I)) N\left(\frac{N}{Q}-1\right)\left(1-\frac{N}{K}\right)-\rho A N \\
\frac{d I}{d t}=\sigma+\frac{c N}{\gamma+N}+b A-m I \\
\frac{d T_{g}}{d t}=p N-d T_{g} .
\end{array}\right.
$$

The equations for $A$ and $T_{g}$ are based on Barbolosi et al. ${ }^{42}$ The first equation comes from the exponencial decay law $A(t)=A_{0} \exp (-\lambda t)$, in that $t_{1 / 2}=1 / a$ and $\lambda=a \log (2)$ is the decay constant. The equation of $A$ does not describe the physical half-life of RAI, but rather its continuous therapeutic effect on cancer cells (see Ref. 42). The treatment consists of only one administration of RAI to ablate remaining thyroid tissue after the total thyroidectomy. The expression $\alpha(1-k \exp (-\beta I))$ represents the proliferation rate of cancer cells under the influence of IL-6, in that $\alpha$ is its maximum value; the parameter $k$, with $0<k<1$, defines its minimum value $\alpha(1-k)$; and $\beta>0$ refers to the rate at which the proliferation rate varies as the IL-6 concentration increases. The parameter $Q$, with $0<Q<K$, is the Allee threshold. When $N<Q$, the term $(N / Q-1)$ is negative. Therefore, a natural decrease occurs in the tumor cell population. The parameter $K$ is the carrying 
capacity of the cancer cells, and $\rho$ is the efficiency rate of iodine on tumor cells. The constant $\sigma$ refers to the natural IL- 6 production, while $c$ is the production rate of this interleukin by tumor mass. Since IL-6 production may occur in multiple ways near the tumor, including the tumor cells, ${ }^{18}$ the term $c N /(\gamma+N)$ represents the IL- 6 production by the tumor mass, where $\gamma$ is the number of cancer cells by which the IL- 6 production rate is half of its maximum. The parameter $b$ refers to the increase of IL- 6 due to RAI treatment and $m$ is its natural elimination rate. The parameter $p$ is the $T_{g}$ production rate by the tumor cells, and $d$ represents the thyroglobulin elimination rate (For more details, see Tables 1, 2 and Fig. 1).

Table 1. Variables used in the model.

\begin{tabular}{ccl}
\hline Variable & Meaning & Units \\
\hline$A$ & Radioiodine therapy activity & $\mathrm{GBq}$ \\
$N$ & Number of the cancer cells & $\mathrm{cells}$ \\
$I$ & Serum IL-6 concentration & $\mathrm{\mu g} / \mathrm{L}$ \\
$T_{g}$ & Serum Tg concentration & $\mathrm{pg} / \mathrm{mL}$ \\
\hline
\end{tabular}

Note: According to the International System of Units $(\mathrm{SI})^{46}$ the symbol $\mathrm{Bq}$ (Becquerel) is the activity referred to a radionuclide and $1 \mathrm{GBq}=10^{3} \mathrm{~Bq}$.

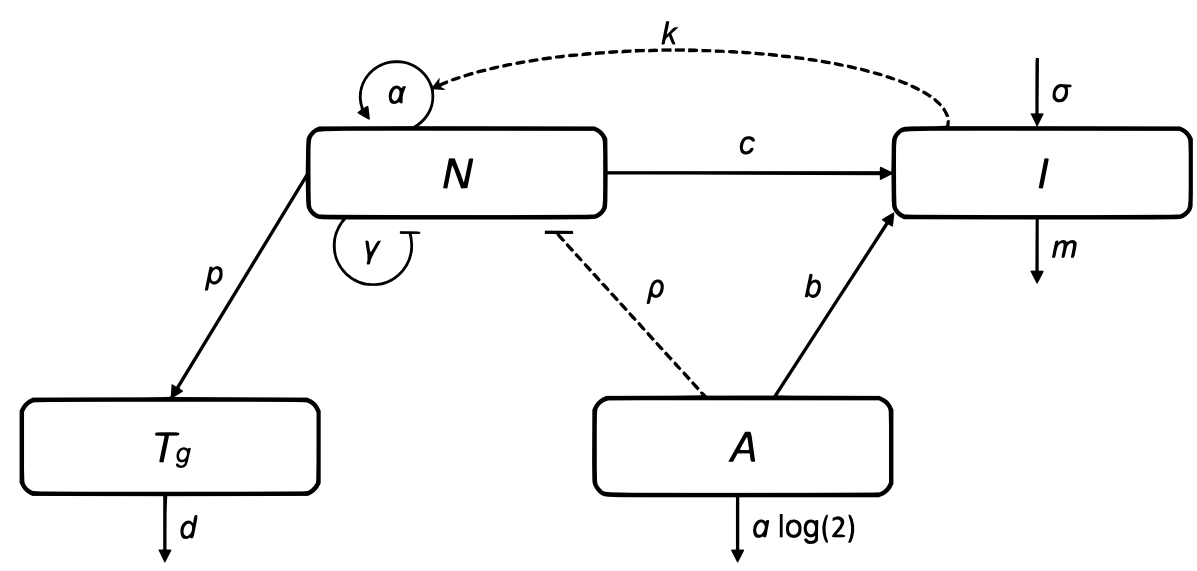

Fig. 1. Schematic model diagram with the dynamics proposed between the activity of RAI, $A$; the number of cancer cells, $N$; and the serum concentrations of IL-6 and thyroglobulin, $I$ and $T g$, respectively. Solid lines represent actions without interaction between compartments and dashed lines, the opposite.

\section{Analysis of the model}

First of all, it is not difficult to see that the solution of the system (2.1) is nonnegative provided that the initial condition is non-negative. To study the equilibrium points of the model (2.1) and their stability, the last equation will not be considered. The variable $T_{g}$ is used in numerical simulations due to its importance as a tumor marker. The equilibrium points are given by: 
- $P_{1}=\left(0,0, \frac{\sigma}{m}\right) \quad$ : extinction of cancer cells,

- $P_{2}=\left(0, Q, \frac{\sigma}{m}+\frac{Q c}{(Q+\gamma) m}\right):$ number unstable cancer cells,

- $P_{3}=\left(0, K, \frac{\sigma}{m}+\frac{K c}{(K+\gamma) m}\right)$ : scenario of metastasis.

The Jacobian matrices and eigenvalues associated to points $P_{1}, P_{2}$ and $P_{3}$, are given below:

$$
\begin{array}{ll}
J\left(P_{1}\right)=\left(\begin{array}{ccc}
-a \ln (2) & 0 & 0 \\
0 & -H_{1} & 0 \\
b & \frac{c}{\gamma} & -m
\end{array}\right), & \text { with }\left\{\begin{array}{l}
\lambda_{1}=-a \ln (2), \\
\lambda_{2}=-m, \\
\lambda_{3}=-H_{1},
\end{array}\right. \\
J\left(P_{2}\right)=\left(\begin{array}{ccc}
-a \ln (2) & 0 & 0 \\
-r Q & H_{2} & 0 \\
b & \frac{c \gamma}{(Q+\gamma)^{2}}-m
\end{array}\right), & \text { with }\left\{\begin{array}{l}
\lambda_{1}=-a \ln (2), \\
\lambda_{2}=-m, \\
\lambda_{3}=H_{2},
\end{array}\right. \\
J\left(P_{3}\right)=\left(\begin{array}{ccc}
-a \ln (2) & 0 & 0 \\
-r K & -H_{3} & 0 \\
b & \frac{c \gamma}{(K+\gamma)^{2}}-m
\end{array}\right), & \text { with }\left\{\begin{array}{l}
\lambda_{1}=-a \ln (2), \\
\lambda_{2}=-m, \\
\lambda_{3}=-H_{3},
\end{array}\right.
\end{array}
$$

where

$$
\begin{aligned}
& H_{1}=\alpha\left(1-k \exp \left(-\frac{\sigma \beta}{m}\right)\right), \\
& H_{2}=(K-Q) \alpha\left(1-k \exp \left(-\beta\left(\frac{\sigma}{m}+\frac{Q c}{(Q+\gamma) m}\right)\right)\right) K^{-1}, \\
& H_{3}=(K-Q) \alpha\left(1-k \exp \left(-\beta\left(\frac{\sigma}{m}+\frac{K c}{(K+\gamma) m}\right)\right)\right) Q^{-1} .
\end{aligned}
$$

Since $0<Q<K$ and $0<k<1$, then $H_{i}>0, i=1,2,3$. Consequently, $P_{1}$ and $P_{3}$ are locally asymptotically stable, while $P_{2}$ is a saddle point. In the first part of linear stability analysis, we consider $A=0$ and obtain scenarios in which complementary treatment with RAI is required or not. Fig. 2 shows the overall system behavior around equilibrium points and the dependence of solutions on their initial conditions and values considered for the parameter $Q$. The dashed curve that contains the squares representing the equilibrium points can be obtained from the variables $N$ and $I$ coordinates at these points. In $N=Q$ there is a vertical line containing point $P_{2}$, separating the two attraction regions which include the points $P_{1}$ and $P_{3}$. 


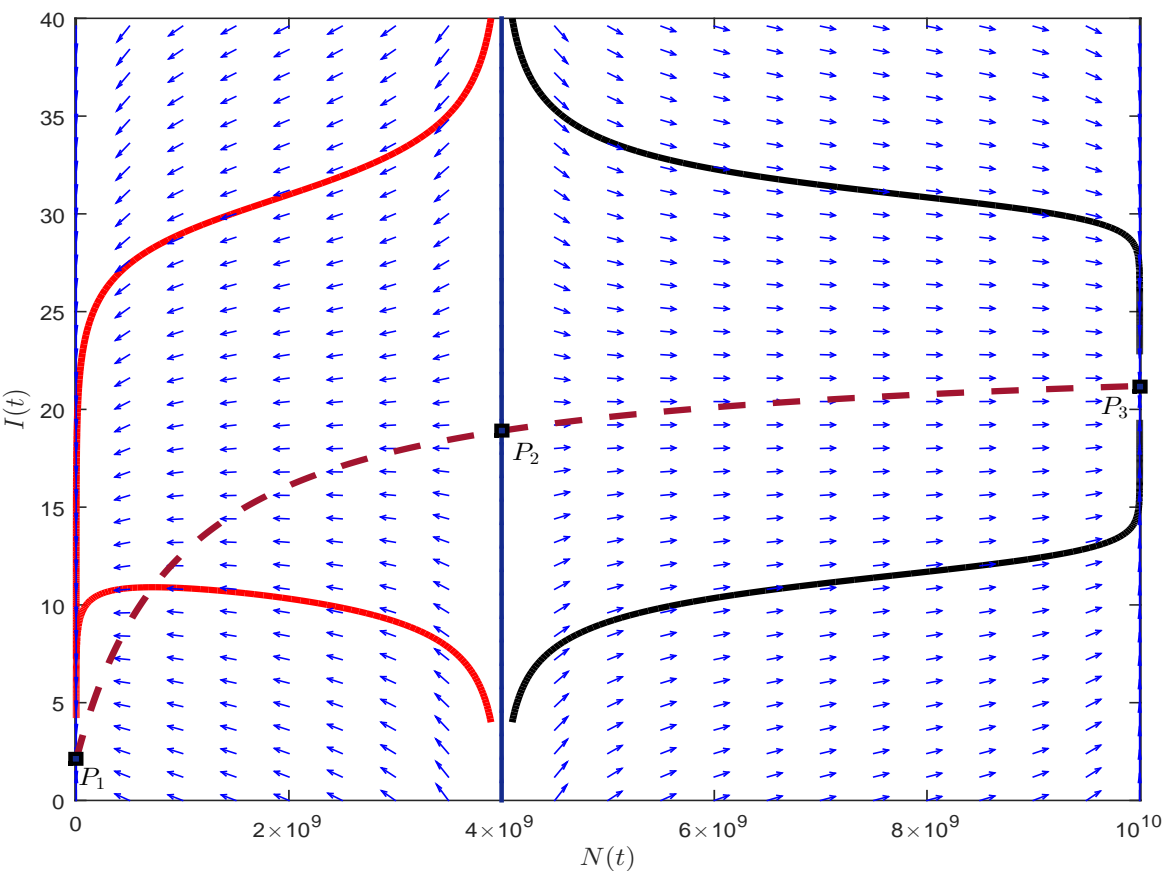

Fig. 2. Phase portrait $N \times I$ using the parameters as indicated in Table 2, except for parameter $Q$, in which is $Q=4 \times 10^{9}$ cells. Solutions obtained from initial conditions $\left(N_{0}, I_{0}\right)=\left(3.9 \times 10^{9}, 2.1\right)$, $\left(4.1 \times 10^{9}, 2.1\right),\left(3.9 \times 10^{9}, 38\right)$ and $\left(4.1 \times 10^{9}, 38\right)$ are represented by solid curves. Equilibrium points are given by $P_{1}=(0,2.1), P_{2}=\left(4 \times 10^{9}, 18.9\right)$ and $P_{3}=\left(10^{10}, 21.2\right)$, and denoted by solid circles. The curve dashed connecting the circles is given by the equation $I=\frac{\sigma}{m}+\frac{N c}{(N+\gamma) m}$.

The critic value $Q$ plays a decisive role in terms of which equilibrium point works as an attractor to the solutions. In this context, we relate this parameter to biological factors that prevent malignant cell growth after surgery. If the number of cancer cells becomes greater than the threshold $Q$, then genetic and epigenetic changes must have occurred to allow them to grow continuously without being impaired by the defense mechanisms, also known as immune evasion. ${ }^{13}$ 

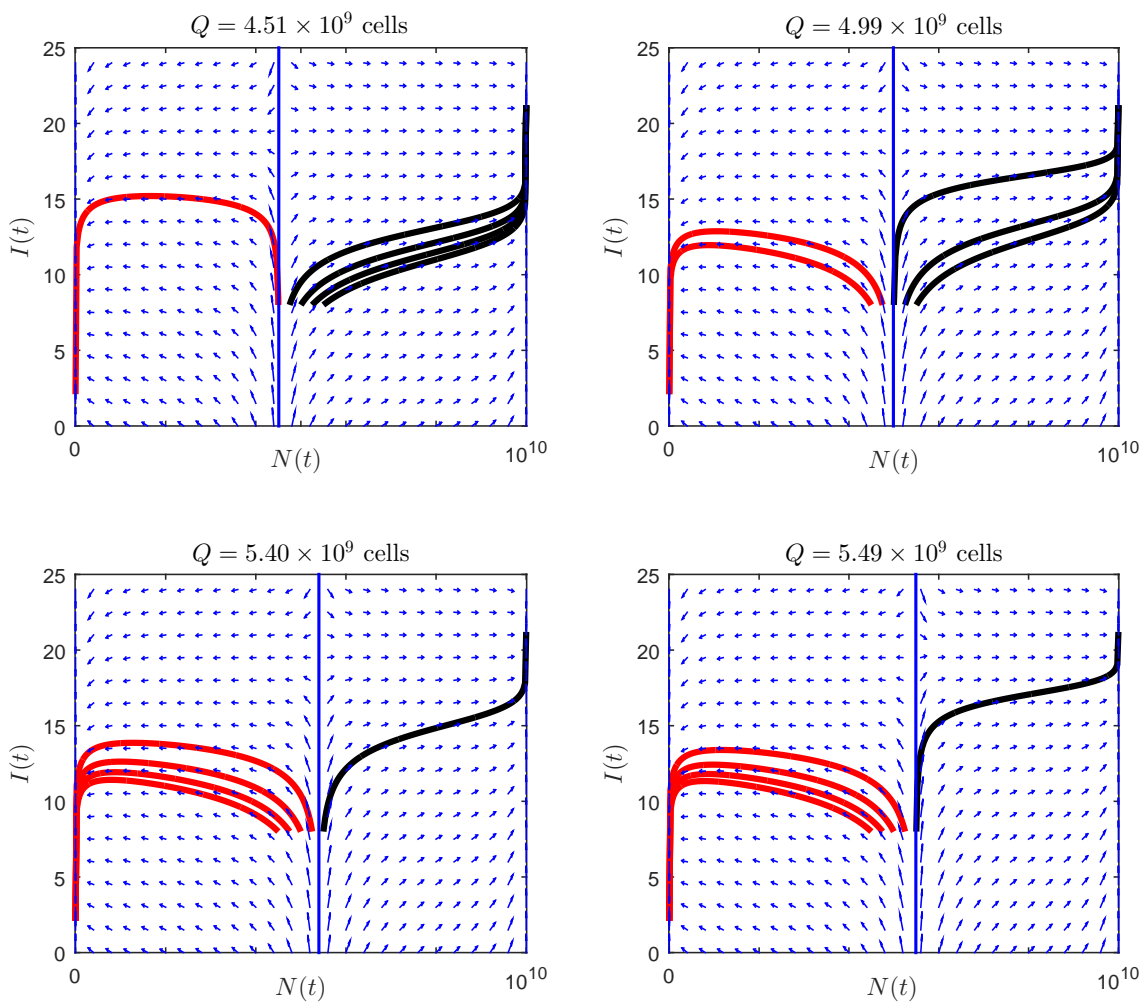

Fig. 3. Influence of parameter $Q$ on solutions representing malignant cell number and IL6 concentrations over time, $t \geq 0$. Solutions obtained using parameters as indicated in Table 2. The parameter $Q$ ranges from $4.0 \times 10^{9}$ to $5.5 \times 10^{9}$ cells. The initial conditions are $N_{0}=4.5 \times 10^{9}, 4.75 \times 10^{9}, 5 \times 10^{9}, 5.25 \times 10^{9}$ and $5.5 \times 10^{9}$ cells, while $I(0)=8 \mathrm{pg} / \mathrm{mL}$. The behavior of the solutions varies depending on the value assumed by $Q$, and as this parameter becomes greater than some $N_{0}$ the corresponding solution leaves the equilibrium point $P_{3}$ and becomes attracted to $P_{1}$, which represents the extinction of the tumor.

Furthermore, when $N \leq Q$, the rate of change of $N$ becomes negative, and, consequently, cancer extinction occurs, as predicted by the Allee effect. The point $P_{2}$ is a saddle and the values chosen for the initial condition $N(0)$ near this point are decisive for the behavior of the solutions, as shown in Fig. 3. In the equilibrium point $P_{1}$ we have $N=0$ which denotes the extinction of the tumor cells. The equilibrium point $P_{3}$ indicates situations where the disease shows resistance over time, overcoming antitumor action of the immune system. 


\section{Introduction of the treatment $A$}

Considering that there is an initial number of cancer cells $N_{0}$ greater than $Q$ and the introduction of treatment $A$, if the radioiodine reduces the tumor cells population to some threshold, denoted by $N^{-}$, then the treatment success is verified, as can be seen in Fig. 4. This results, however, raises an important question: is there an optimal RAI activity according to each patient, or the more RAI used, the higher the chances of success and the faster cancer extinction occurs regardless of the particularities of the patient? According to the literature, many factors are involved in this process, as seen in the next section.

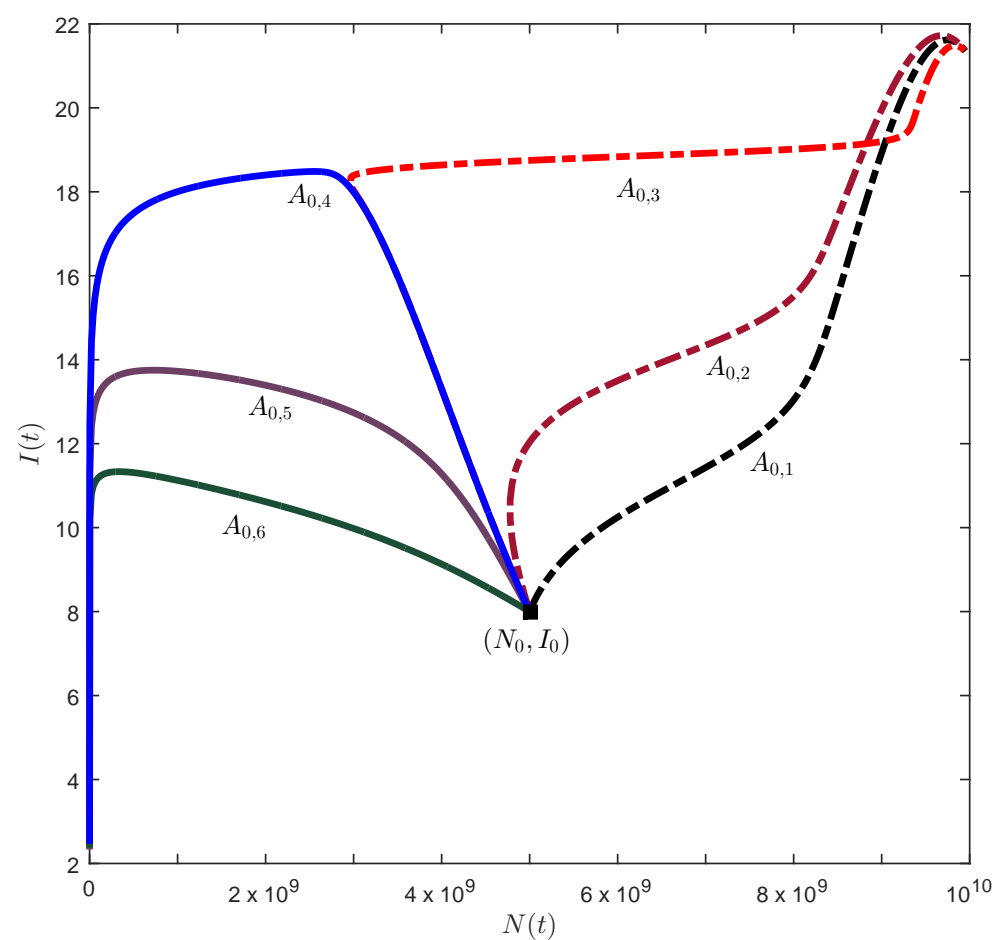

Fig. 4. The number of malignant cells and IL-6 concentrations over time, $t \geq 0$, at different RAI doses. The model (2.1) presents scenarios in which cancer is driven to extinction or not, depending on the RAI doses used. The parameters used are indicated in Table 2, except for the parameter $Q$, in which is $Q=2 \times 10^{9}$ cells. Initial conditions are given by $N_{0}=5 \times 10^{9}$ cells, $I_{0}=8 \mathrm{pg} / \mathrm{mL}$ and $A_{0,1}=3.7, A_{0,2}=4.3, A_{0,3}=4.4132407, A_{0,4}=4.4132409, A_{0,5}=4.5$, and $A_{0,6}=5.55 \mathrm{GBq}$.

The bifurcation observed in Fig. 4 applying the parameters $A_{0,3}$ and $A_{0,4}$, could also be verified using less specific values. However, from the values used, we can see the exact instant when the solution alters the equilibrium point attractor. Moreover, we can also note the entry of treatment as a new variable that strangles the regions 
previously considered as the basin of attraction, where the vertical line $N=Q$ is the separatrix. With $A_{0,4}$ the solution previously attracted to point $P_{3}$ migrates to the other region of asymptotic stability. The bifurcation then occurs when the number of cancer cells is, approximately, $N^{-}=3 \times 10^{9}$ cells, a number different from $Q$ with the scales considered. The value of $N^{-}$where the stability change occurs is not fixed, but depends on the parameters, especially those involved in cancer cell proliferation and elimination.

\section{Results and discussion}

In order to perform some of the numerical simulations, we collect data on interleukin-6 (IL-6) serum concentrations presented in Morais et al., ${ }^{43}$ consisting of the average IL- 6 concentration in individuals under diverse conditions. The data obtained from this study were: concentration of $2.10 \mathrm{pg} / \mathrm{mL}$ for IL- 6 in healthy subjects; $7.98 \mathrm{pg} / \mathrm{mL}$ for IL-6 concentration in papillary thyroid cancer (PTC) patients, measured after the thyroidectomy but before RAI treatment; and $22.99 \mathrm{pg} / \mathrm{mL}$ after RAI treatment. The initial condition $I_{0}=7.98 \mathrm{pg} / \mathrm{mL}$ is considered in the simulations because it refers to the target stage of this PTC treatment study.

According to Weinberg, ${ }^{44}$ angiogenesis begins when the tumor has about $10^{7}$ cells and is palpable when it reaches $10^{9}$ cells. Wilkie and Hahnfeldt ${ }^{45}$ used a cell number of $10^{10}$ for the carrying capacity of cancer in the mathematical models employed to study acute myeloid leukemia. After thyroidectomy, some residual thyroid tissue remains in the patient. Nodules with a reservoir of cancer cells sometimes persist, with the possibility of metastasis occurring. ${ }^{8}$ Barbolosi et al..$^{42}$ considered the average number of $N_{0}=1.12 \times 10^{9}$ cancer cells in patients after the thyroidectomy and with the presence of metastasis. We assume in our study three values as the initial number of cancer cells after the thyroidectomy and before RAI treatment: $N_{0,1}=6 \times 10^{8}, N_{0,2}=9 \times 10^{8}$, and $N_{0,3}=1.12 \times 10^{9}$ cells. Thus, three stages of PTC under RAI treatment are assumed.

Regarding the RAI activity assumed in the simulations, the doses of $A_{0,1}=3.7$, $A_{0,2}=5.55$, and $A_{0,3}=7.4 \mathrm{GBq}$ are considered. These values presented in Morais et $a l .{ }^{43}$ as the most used doses during the treatment of $31 \mathrm{PTC}$ patients. In Barbolosi et al. study, ${ }^{42}$ RAI activities used in a group of 50 PTC patients ranged from 3.7 to $5.5 \mathrm{GBq}$.

According to Haugen et al., ${ }^{8}$ specific levels of thyrogloblulin that distinguish normal residual tissue from those with cancer are unknown, albeit increasing $\mathrm{Tg}$ values over time may indicate cancer persistence. In patients undergoing thyroidectomy and RAI treatment, the criteria for disease-free status include low serum $\mathrm{Tg}$ levels, $\mathrm{Tg}<1 \mathrm{\mu g} / \mathrm{L}$, in the absence of interfering antibodies. Therefore, the value of $10 \mu \mathrm{g} / \mathrm{L}$ is considered for $T_{g, 0}$ as the initial condition in numerical simulations.

The parameters of the model (2.1) received values as found in the literature or assume biologically relevant values to allow the system to illustrate some expected results during the treatment (Table 2). The model's numerical simulations 
are performed Runge-Kutta fourth-order method, using step-size $h=0.01$.

Table 2. Parameters and used values in the model's numerical simulations.

\begin{tabular}{cccl}
\hline Parameter & Value & Unity & Reference/comment \\
\hline$a$ & $1.69 \times 10^{-2}$ & $\mathrm{t}^{-1}$ & Ref. 42 \\
$\alpha$ & $7.5 \times 10^{-1}$ & ${\text { cells } \times \mathrm{t}^{-1}}^{-1}$ & - \\
$k$ & $7.2 \times 10^{-1}$ & - & - \\
$\beta$ & $2 \times 10^{-3}$ & $(\mathrm{pg} / \mathrm{mL})^{-1}$ & - \\
$Q$ & $5 \times 10^{8}$ & cells & based on Ref. 45 \\
$K$ & $1 \times 10^{10}$ & cells & Ref. 45 \\
$\rho$ & $4.07 \times 10^{-2}$ & $(\mathrm{GBq} \times \mathrm{t})^{-1}$ & based on Ref. 42 \\
$\sigma$ & $5 \times 10^{-2}$ & $\mathrm{pg} \times(\mathrm{mL} \times \mathrm{t})^{-1}$ & - \\
$c$ & $5 \times 10^{-1}$ & $\mathrm{pg} \times(\mathrm{mL} \times \mathrm{t})^{-1}$ & - \\
$\gamma$ & $1 \times 10^{9}$ & cells & - \\
$b$ & $2 \times 10^{-2}$ & $\mathrm{pg} \times(\mathrm{mL} \times \mathrm{t} \times \mathrm{GBq})^{-1}$ & - \\
$m$ & $2.38 \times 10^{-2}$ & $\mathrm{t}^{-1}$ & - \\
$p$ & $3.86 \times 10^{-9}$ & $\mu \mathrm{g} \times(\mathrm{L} \times \mathrm{t})^{-1}$ & Ref. 42 \\
$d$ & $3.19 \times 10^{-1}$ & $\mathrm{t}^{-1}$ & Ref. 42 \\
\hline
\end{tabular}

Note: According to the International System of Units $(\mathrm{SI})^{46}$ the following conversions are worth: $1 \mathrm{pg}=10^{-15} \mathrm{~kg}, 1 \mu \mathrm{g}=10^{-9} \mathrm{~kg}$ and $1 \mathrm{~mL}=10^{-3}$ L. The dash used in the reference column means that no values were found in the literature for this parameter.

The analysis began by considering a scenario with the absence of treatment to verify a possible evolution of remnant cancer cells at different risk stages after total thyroidectomy. Due to the Allee effect, two situations are considered. In the first, the values for the initial number of cancer cells, represented by $N_{0, i, i=1,2,3}$, indicate situations in which the tumor mass is quite advanced, with possible foci in other parts of the body, especially when considered $N_{0,3}$. In the second situation, we considered a tumor with well-localized malignant cells, in which the thyroidectomy eliminated most cancer cells in the thyroid gland, with only $10^{6}$ cells remaining.

Furthermore, the $Q \gg 10^{6}$ in the second situation entails an active and effective defense system as well as the absence of factors necessary for the growth of the tumor population, such as angiogenesis. ${ }^{47}$ Moreover, because the tumor mass is not spread, it is likely that this cancer is in its early stages or is a low-risk PTC,${ }^{8}$ and therefore RAI treatment is not required to eliminate remnants of cancer, as seen in Fig. 5. However, when the initial number for cancer cells is $N_{0}>Q$, these populations continue to grow toward the carrying capacity, meaning the development of metastasis. 


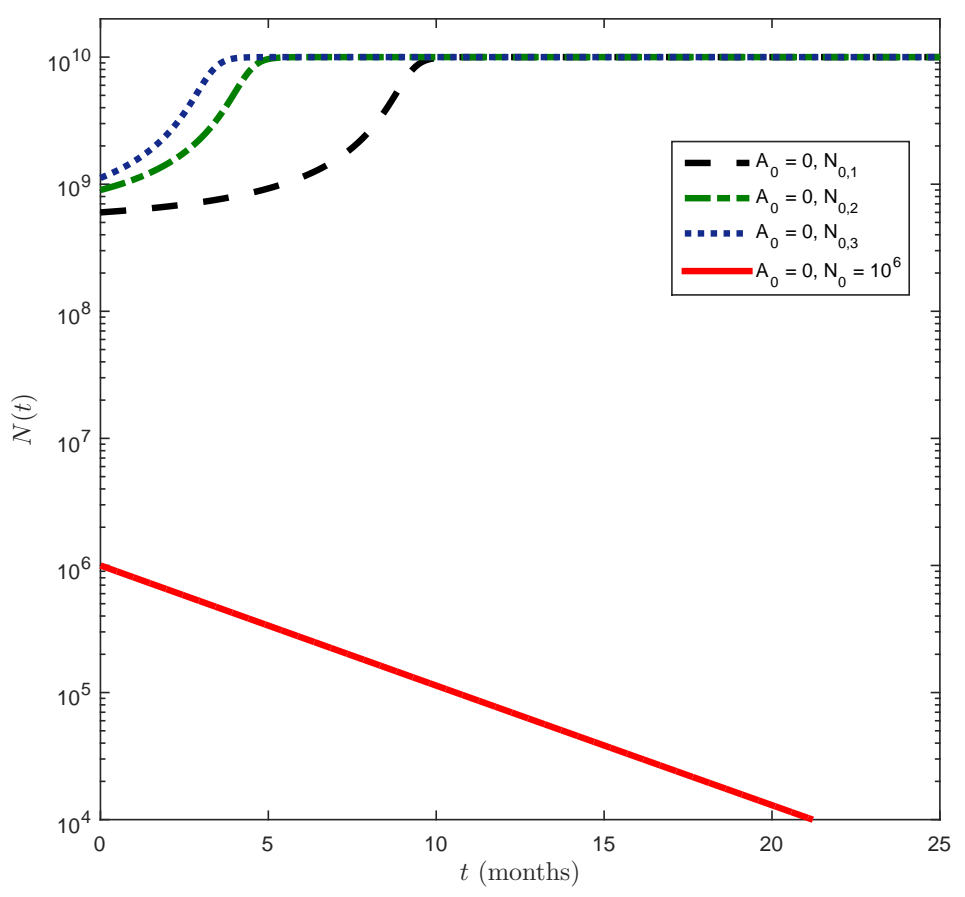

Fig. 5. Evolution of cancer cells in the absence of treatment over time $t \geq 0$. The parameters used are indicated in Table 2. Initial conditions are given by $N_{0,1}=6 \times 10^{8}, N_{0,2}=9 \times 10^{8}$, $N_{0,3}=1.12 \times 10^{9}$ and $N_{0}=10^{6}$ cells, $I_{0}=7.98 \mathrm{pg} / \mathrm{mL}$ and $A_{0}=0 \mathrm{GBq}$. The time difference that the populations $N_{0,1}$ and $N_{0,3}$ take to reach carrying capacity is approximately 6 months. In the situation where thyroidectomy has eliminated most cancer cells, the body is in a position to lead the remaining cells, as used in this example, $N(0)=10^{6}$, to extinction.

Next, we simulate the use of RAI treatment (see Fig. 6). With the initial dose $A_{0,1}$, only the solution corresponding to the initial condition $N_{0,1}$ approaches the equilibrium point $P_{1}$, while the other solutions evolve towards point $P_{3}$. When we use the dose $A_{0,2}$, the solution corresponding to $N_{0,2}$ also approaches point $P_{1}$ and the same happens to solution corresponding to $N_{0,3}$ when $A_{0,3}$ is used (see Fig. 6a). Hence, it is clear that part of a successful treatment is linked to the dose used in the therapy. However, following this dynamic, if we consider the value for $N_{0}$ closer to $K$, the dose required to eliminate the disease could be physically impractical due to aggressive side effects, and, consequently, the treatment should be performed through various spaced RAI applications, as considered in Barbolosi et al. ${ }^{42}$ From numerical simulations, we can also verify scenarios with a possible association between the dose used in RAI treatment and its effectiveness in destroying the cancer cells (see Fig. 6b). 

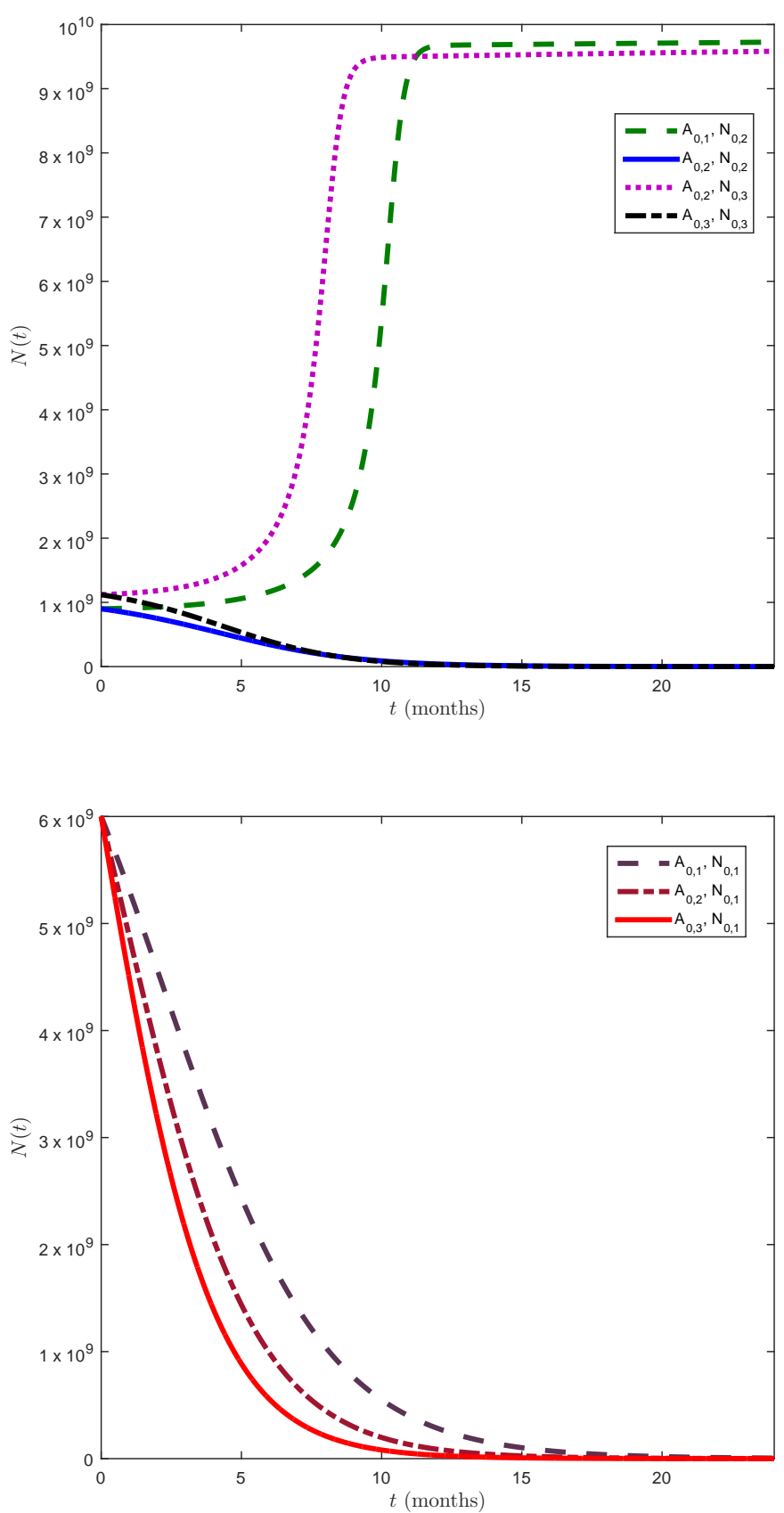

Fig. 6. Growth or decrease in the number of malignant cells according to RAI activity used over time, $t \geq 0$. The parameters used are indicated in Table 2 . The values used in the initial conditions are given by $N_{0,1}=6 \times 10^{8}, N_{0,2}=9 \times 10^{8}$, and $N_{0,3}=1.12 \times 10^{9}$ cells; $I_{0}=7.98 \mathrm{pg} / \mathrm{mL}$ and $A_{0,1}=3.7, A_{0,2}=5.55$, and $A_{0,3}=7.4 \mathrm{GBq}$. Despite the same initial conditions for $N(0)$, in some situations successful treatment depends on the RAI activity administered to patients. 
The use of solutions only formed from initial condition $N_{0,1}$, shown in Fig. $6 \mathrm{~b}$, aims to enable us to monitor RAI destructive force when its doses are more substantial. From the database obtained from the numerical simulations resulting files, we observed that for a reduction of $N$ below $10^{4}$ cells the time spent in months for $A_{0,1}, A_{0,2}$ and $A_{0,3}$, were 36,29 , and 24 months, respectively. Thus, the model presents scenarios with a positive association between the amount of RAI used and the tumor extinction time. Notwithstanding, it must be noted that the system (2.1) does not consider aspects such as side effects of each RAI amount used, genetic mutations and the patient's physical condition to support such doses of the drug.

Fig. 7 describes a few scenarios with the association between cancer cell number and thyroglobulin level in the patients. These results agree with the use of $\mathrm{Tg}$ as a means of evaluating treatment outcomes. ${ }^{8}$ The value reached by variable $T_{g}$ when the tumor population approaches the carrying capacity depends on values used for parameters $p, d$, and $K$. When considered $A_{0,3}$ and $N_{0,2}$, the level of $T_{g}$ falls below $2 \mu \mathrm{g} / \mathrm{L}$ after 9 months, and continue to decrease over time.

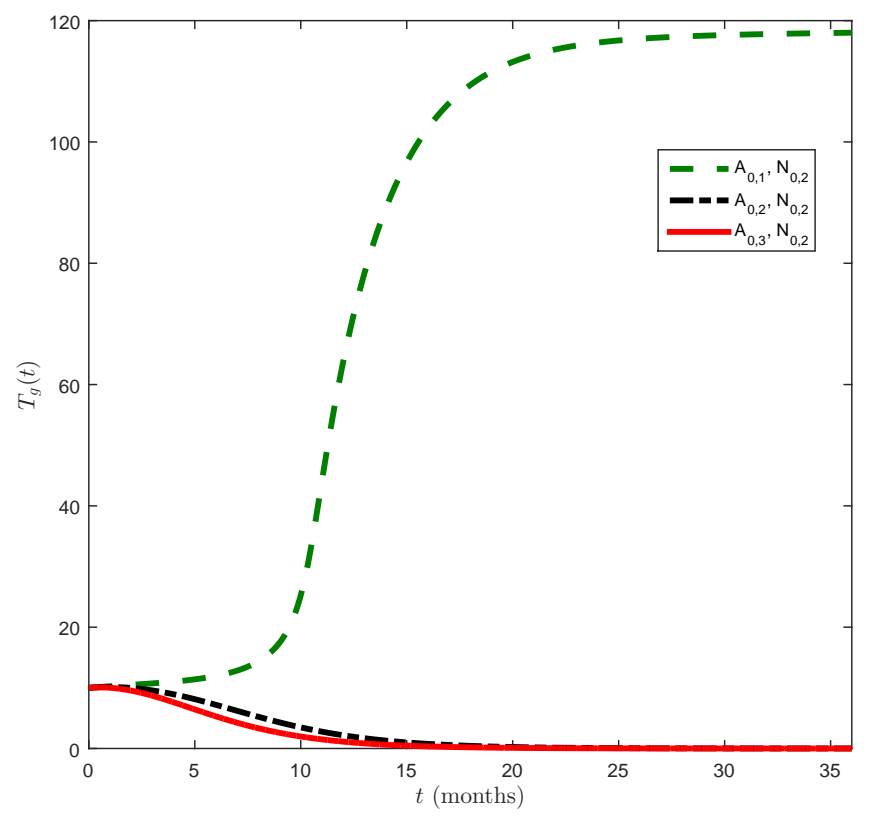

Fig. 7. Thyroglobulin concentration in patients under treatment with RAI over time $t \geq 0$. The parameters used are indicated in Table 2 . The values used in the initial conditions are given by $N_{0,2}=9 \times 10^{8}$ cells, $I_{0}=7.98 \mathrm{pg} / \mathrm{mL}, A_{0,1}=3.7, A_{0,2}=5.55$, and $A_{0,3}=7.4 \mathrm{GBq}$, and $T_{g, 0}=10 \mu \mathrm{g} / \mathrm{L}$. When RAI dose is sufficient to eliminate cancer cells, the level of Tg decreases as the cancer cell population is eliminated.

Next, Fig. 8 presents different scenarios with IL-6 levels over time. From the 
solution curves, we note that, although tumor mass triggers a higher production of this interleukin compared to the presence of iodine in the body, when used $A_{0,3}$ with $N_{0,2}$ the production of IL-6 tends to approach the solution obtained from $N_{0,3}$. This fact suggests two observations: firstly, that altered IL-6 levels may remain for a long time and, secondly, that side effects triggered by increased inflammation due to the higher dose of RAI also contribute to higher levels of interleukin.

Another fact to note is the slower rate in which IL-6 levels increases as cancer progresses to its carrying capacity. Regarding this slow increase, the IL-6 limit given by the value obtained from the model $(2.1)$ is $\frac{\sigma+c}{m} \approx 23.1 \mathrm{pg} / \mathrm{mL}$, and of all simulations performed, the highest value obtained for the variable $I$ was, approximately, $20 \mathrm{pg} / \mathrm{mL}$, with this value being verified as a plateau level over time.

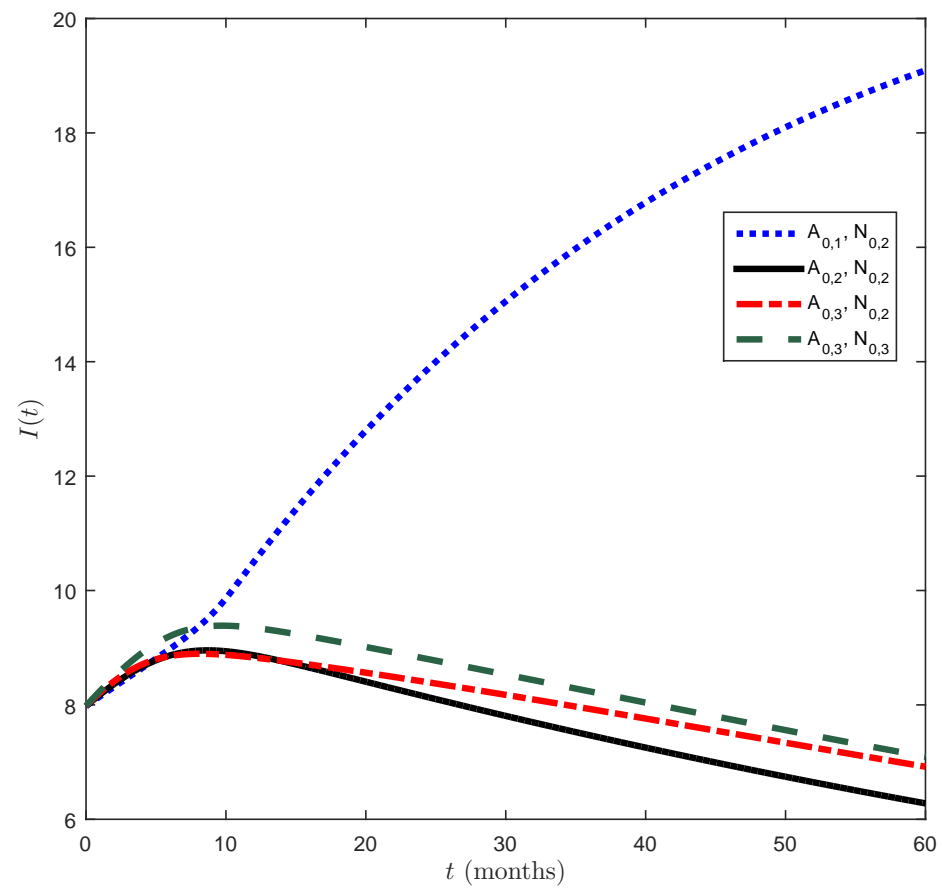

Fig. 8. IL-6 concentration in PTC patients undergoing RAI treatment over time, $t \geq 0$. The parameters used are indicated in Table 2. The values used in the initial conditions are given by: $N_{0,2}=9 \times 10^{8}$ and $N_{0,3}=1.12 \times 10^{9}$ cells; $I_{0}=7.98 \mathrm{pg} / \mathrm{mL} ;$ and $A_{0,1}=3.7, A_{0,2}=5.55$, and $A_{0,3}=7.4 \mathrm{GBq}$. From the solutions, we observed that the tumor mass is primarily responsible for the increase of this interleukin levels.

The results obtained through numerical simulations from the model (2.1) present 
a wide range of scenarios; however, solutions as those obtained in Fig. 6 do not intend to end the discussion of treatment success, perhaps only suggest larger doses to eliminate the disease without taking into account the side effects of the higher dosage. There are other variables not considered in the model as the natural concentration of sodium iodide symporter (NIS), which is crucial for iodine uptake by thyroid cells. ${ }^{48}$ Morais et al. ${ }^{43}$ studied the levels of NIS glycoprotein as a first step in deciding whether to use RAI in the PTC treatment. Furthermore, an assessment of tumor cells' NIS expression by molecular imaging, as suggested by Barbolosi et $a l .,{ }^{42}$ is presented as a defining factor on the effectiveness of radioiodine therapy. Therefore, considering factors like these in the interpretation of results, it is necessary as a way to complement for some variables not included in the proposed model. The results shown in Figs. 7 and 8 aim to show general behavior over Tg and IL-6 concentrations over time, however, it does not necessarily reflect the results found in patients. In general, the time spent for cancer elimination ranged from 12 to 40 months; therefore, it is understandable that Tg and IL-6 levels also take time slowly decrease. Finally, relapses situations can be understood as presented via solution from $A_{0,1}$ and $N_{0,2}$ in Figs. 6 and 8, where just seven months after starting treatment, the number of cancer cells and IL- 6 concentrations shows growth at an advanced rate.

\section{Conclusions}

Using a mathematical model based on the RAI treatment applied to PTC, we evaluated the parameters of RAI activity, IL-6 levels and the number of remnant cancer cells in determining the effectiveness of treatment. The simulations performed associated the time taken to eliminate tumor cells with the RAI activity used. Notwithstanding, we have also obtained scenarios with the lowest possible activity for $A_{0}$ resulting in a successful treatment. These results corroborated new treatment proposals with the least possible side effects. Besides the treatment and, the application of the Allee effect, other factors that promote the reduction of cancer cells were considered in the model from the parameter $Q$. In this sense, simulations presented underscore the importance of natural processes or defenses in controlling or eliminating malignant cells. Finally, from the parameters $k$ and $\beta$, we observed how components of tumor mass may contribute to the development of tumors, increasing the aggressiveness and proliferation rate of cancer cells via IL-6 levels. Thus, the proposed model presented new elements in the discussion about the optimal amount of RAI used in PTC patients; the importance of natural defense mechanisms for the elimination of post-surgery remnant cells, with and without the use of RAI; and presented scenarios in that IL-6 is considered a favorable agent for tumor progression. 


\section{Acknowledgments}

The authors would like to thank Malay Banerjee and Calliandra Maria de Souza Silva for their important and productive discussions, the Instituto Federal de Mato Grosso (IFMT) and INRIA-France. This study was financed in part by the Coordenação de Aperfeiçoamento de Pessoal de Nível Superior - Brasil (CAPES) Finance Code 001.

\section{References}

1. Rahib L, Smith BD, Aizenberg R, Rosenzweig AB, Fleshman JM, Matrisian LM, Projecting cancer incidence and deaths to 2030: the unexpected burden of thyroid, liver, and pancreas cancers in the United States, Cancer Res 74(11):2913-2921, 2014. doi: 10.1158/0008-5472.CAN-14-0155.

2. Siegel R, Ma J, Zou Z, Jemal A, Cancer statistics, 2014, CA Cancer J Clin 64:9-29, 2014. doi: 10.3322 /caac. 21208

3. Wiltshire JJ, Drake TM, Uttley L, Balasubramanian SP, Systematic review of trends in the incidence rates of thyroid cancer, Thyroid 26(11):1541-1552, 2016.

4. Lim H, Devesa SS, Sosa JA, Check D, Kitahara CM, Trends in thyroid cancer incidence and mortality in the United States, 1974-2013, JAMA 317(13):1338-1348, 2017. doi: 10.1001/jama.2017.2719.

5. Pellegriti G, Frasca F, Regalbuto C, Squatrito S, Vigneri R, Worldwide increasing incidence of thyroid cancer: update on epidemiology and risk factors, $J$ Cancer Epidemiol 2013(965212):1-10, 2013. doi: 10.1155/2013/965212

6. Ferrari SM, Fallahi P, Politti U, Materazzi G, Baldini E, Ulisse S, Miccoli P, Antonelli A, Molecular targeted therapies of aggressive thyroid cancer, Front Endocrinol 6:176, 2015 doi: 10.3389 /fendo. 2015.00176

7. Pusztaszeri M, Auger M, Update on the cytologic features of papillary thyroid carcinoma variants, Diagn Cytopathol 45(8):714-730, 2017. doi: 10.1002/dc.23703

8. Haugen B, Alexander E, Bible K, Doherty G, Mandel S, Nikiforov Y, Pacini F, Randolph G, Sawka A, Schlumberger M, Schuff K, Sherman S, Sosa J, Steward D, Tuttle R, Wartofsky L, 2015 American Thyroid Association management guidelines for adult patients with thyroid nodules and differentiated thyroid cancer, Thyroid 26(1):1-133, 2016. doi: 10.1089/thy.2015.0020

9. Mumtaz M, Lin LS, Hui KC, Khir ASM, Radioiodine I-131 for the therapy of Graves' disease, Malays J Med Sci 16(1):25-33, 2009.

10. Wishart DS, Knox C, Guo AC, Shrivastava S, Hassanali M, Stothard P, Chang Z, Woolsey J, Drugbank: a comprehensive resource for in silico drug discovery and exploration, Nucleic Acids Res 34(Database issue):D668-D672, 2006.

11. Blumhardt R, Wolin EA, Phillips WT, Salman UA, Walker RC, Stack BC, Metter D, Current controversies in the initial post-surgical radioactive iodine therapy for thyroid cancer: a narrative review, Endocr Relat Cancer 21(6):R473-R484, 2014.

12. Tuttle RM, Lopez N, Leboeuf R, Minkowitz SM, Grewal R, Brokhin M, Omry G, Larson S, Radioactive iodine administered for thyroid remnant ablation following recombinant human thyroid stimulating hormone preparation also has an important adjuvant therapy function, Thyroid 20(3):257-263, 2010.

13. Dunn GP, Old LJ, Shreiber RD, The three Es of cancer immunoediting, Annu Rev Immunol 22:329-360, 2004.

14. Yu H, Zhang G, Jin Y, He C, Wei T, DI N, LI S, Immune status in patients with thyroid carcinoma and its correlation with clinicopathologic characteristics, Biomed 
Res 28(16):7286-7294, 2017.

15. Tanaka T, Narazaki M, Kishimoto T, IL-6 in inflammation, immunity, and disease, CSH Perspect Biol 6(10):a016295, 2014.

16. Yoshida A, Asaca T, Masuzawa C, Kawahara S, Yanoma S, Harada M, Okamoto T, Production of cytokines by thyroid carcinoma cell lines, J Surg Oncol 55:104-107, 1994.

17. Lumachi F, Basso SMM, Orlando R, Cytokines, thyroid diseases and thyroid cancer, Cytokine 50:229-233, 2010.

18. Fisher DT, Appenheimer MM, Evans SS, The two faces of IL-6 in the tumor microenvironment, Semin Immunol 26(1):38-47, 2014.

19. Kobawala TP, Trivedi TI, Gajjar KK, Patel DH, Patel GH, Ghosh NR, Significance of interleukin-6 in papillary thyroid carcinoma, J Thyroid Res 6178921:1-12, 2016.

20. Martins MB, Marcello MA, Batista FA, Peres KC, Meneghetti M, Ward MAL, Etchebehere ECSC, Da Assumpção LVM, Ward LS, Serum interleukin measurement may help identify thyroid cancer patients with active disease, Clin Biochem 52(8):1-7, 2018.

21. Grivennikov SI, Karin M, Inflammation and oncogenesis: a vicious connection, Curr Opin Genet Dev 20(1):65-71, 2010.

22. Provatopoulou X, Georgiadou D, Sergentanis TN, Kalogera E, Spyridakis J, Gounaris A, Zografos GN, Interleukins as markers of inflammation in malignant and benign thyroid disease, Inflamm Res 63(8):667-674, 2014.

23. Jarrett AM, Lima EABF, Hormuth DA, McKenna MT, Feng X, Ekrut DA, Resende ACM, Brock A, Yankeelov TE, Mathematical models of tumor cell proliferation: A review of the literature, Expert Rev Anticancer Ther 18(12):1271-1286, 2018. doi: 10.1080/14737140.2018.1527689

24. Korolev KS, Xavier JB, Gore J, Turning ecology and evolution against cancer, Nat Rev Cancer 14(5):371-380, 2014. doi: 10.1038/nrc3712.

25. Johnson KE, Howard G, Mo W, Strasser MK, Lima EABF, Huang S, Brock A, Cancer cell population growth kinetics at low densities deviate from the exponential growth model and suggest an Allee effect, PLoS Biol 17(8):e3000399, 2019. doi: 10.1371/journal.pbio.3000399.

26. Feng P, Dai Z, Wallace D, On a 2D model of avascular tumor with weak Allee effect, J Appl Math 2019(9581072):1-13, 2019. doi: 10.1155/2019/9581072

27. Bottger K, Hatzikirou H, Voss-Bohme A, Cavalcanti-Adam EA, Herrero MA, Deutsch A, An emerging Allee effect is critical for tumor initiation and persistence, PLoS Comput Biol 11(9):e1004366, 2015. doi: 10.1371/journal.pcbi.1004366

28. Neufeld Z, von Witt W, Lakatos D, Wang J, Hegedus B, Czirok A, The role of Allee effect in modelling post resection recurrence of glioblastoma, PLoS Comput Biol 13(11): e1005818, 2017. doi: 10.1371/journal.pcbi.1005818

29. Stephens PA, Sutherland WJ, Freckleton RP, What is the Allee effect? Oikos 87: 185-190, 1999.

30. Kramer AM, Dennis B, Liebhold AM, Drake JM, The evidence for Allee effects, Popul Ecol 51(3):341-354, 2009.

31. Altrock P, Liu L, Michor F, The mathematics of cancer: integrating quantitative models, Nat Rev Cancer 15:730-745, 2015.

32. Barbolosi D, Ciccolini J, Lacarelle B, Barlési F, André N, Computational oncologymathematical modelling of drug regimens for precision medicine, Nat Rev Clin Oncol 13:242-254, 2016.

33. Danziger L, Elmegreen GL, The thyroid-pituitary homeostatic mechanism, Springer 18:1-13, 1956. 
34. Friedman A, Mathematical biology: modeling and analysis, American Mathematical Society, Columbus, 2018.

35. Silva JG, Morais RM, Silva ICR, Mancera PFA, Mathematical models applied to thyroid cancer, Biophys Rev 11(2):183-189, 2019.

36. Lamooki GRR, Shirazi AH, Mani AR, Dynamical model for thyroid, Commun Nonlinear Sci Numer Simul 22:297-313, 2015.

37. Jamshidi AA, Lamouki GRR, A data driven diagnosis tool for thyroid hormones, Comput Biol Med 103:301-311, 2018. doi: 10.1016/j.compbiomed.2018.09.023.

38. Ruggieri M, Fumarola A, Straniero A, Maiuolo A, Coletta I, Veltri A, Di Fiore A, Trimboli P, Gargiulo P, Genderini M, D'armiento M, The estimation of the thyroid volume before surgery: an important prerequisite for minimally invasive thyroidectomy, Langenbeck Arch Surg 393:721-724, 2008.

39. Gavriloaia GV, Gavriloaia MR, Multispectral acoustic investigation of a thyroid geometrical model, Proceedings of IEEE Engineering in Medicine and Biology Society, Argentina, pp. 585-588, 2010.

40. Chen CY, Chang PJ, Changlai SP, Pan LK, Effective half life of iodine for five thyroidectomy patients using an in vivo gamma gamera approach, J Radiat Res 48(6):485493, 2007.

41. Traino AC, Di Martino FA, Dosimetric algorithm for patient-specific ${ }^{131} \mathrm{I}$ therapy of thyroid cancer based on a prescribed target-mass reduction, Phys Med Biol 51:6449$6456,2006$.

42. Barbolosi D, Summer I, Meille C, Serre R, Kelly A, Zerdoud S, Bournaud C, Schvartz C, Toubeau M, Toubert ME, Keller I, Taieb D, Modeling therapeutic response to radioiodine in metastatic thyroid cancer: a proof-of-concept study for individualized medicine, Oncotarget 8(24):39167-39176, 2017.

43. Morais RM, Polimorfismo genético dos genes P53, IL6 e TNFA em pacientes portadores do câncer papilífero da tireoide submetidos a iodoterapia em uma amostra do Distrito Federal, Master thesis, University of Brasilia, Brazil, 2018.

44. Weinberg RA, The biology of cancer, Garland Science, New York, 2006.

45. Wilkie KP, Hahnfeldt P, Mathematical models of immune-induced cancer dormancy and the emergence of immune evasion, Interface Focus 3(4):20130010, 2013.

46. Taylor BN, Thompson A, The international system of units (SI). NIST special publication 330, National Institute of Standards and Technology, Washington, 2008.

47. Folkman J, Klagsbrun M, Angiogenic factors, Science 235(4787):442-447, 1987.

48. de Morais RM, Sobrinho AB, de Souza Silva CM, de Oliveira JR, da Silva ICR, de Toledo Nóbrega O, The role of the NIS (SLC5A5) gene in papillary thyroid cancer: a systematic review, Int $J$ endocrinol 2018:1-11, 2018. 